\title{
Special issue on land reclamation in ecological fragile areas
}

\author{
Zhenqi Hu ${ }^{1}$
}

Published online: 26 April 2018

(C) The Author(s) 2018

Coal is the most important energy in China, accounting for about $60 \%$ of energy consumption, which is about half of the total coal output in the world. With the excavation of coal resources, a lot of land was damaged and serious environmental problems were produced. Thus, coal mined land reclamation has become the important task for achieving the target of green mining in China. As most of coal mines locate in ecological fragile areas, the ecological damages might even more serious. Therefore, this special issue focus on land reclamation in ecological fragile areas.

Land reclamation is an important issue in the world. As the executive secretary of Professional Committee of Land Reclamation and Ecological Restoration of China Coal Society, we put forward a serious international symposium on land reclamation and ecological restoration for promoting the international cooperation and exchanges every 3 years. The first one was held in Beijing 2014 (LRER 2014) and the second one was held in Xi' an 2017(LRER 2017), which have promoted the communication of land reclamation and ecological restoration technology and experience internationally, advanced and renovated reclamation and ecological restoration technology and practice, accelerated international collaboration in this field. The theme of the second international symposium on land reclamation and ecological restoration was "Land Reclamation in Fragile Areas". Thus, we select some of valuable papers from the symposium for publishing this special

Zhenqi Hu

huzq1963@163.com

1 Institute of Land Reclamation and Ecological Restoration, China University of Mining and Technology (Beijing), D11 Xueyuan Road, Haidian District, Beijing 100083, China issue so that more and more people to pay much attention on this subject.

This special issue published 11 papers related to different problems in the field of land reclamation. The first and second papers are related to legislation of land reclamation. Reclamation regulation in the USA was enacted in 1977, which is well-known law for land reclamation. The first one presented some of the basic changes made in reclamation programs over the last 40 years in the State of Wyoming, USA based on the federal regulation entitled "Surface Mining Control and Reclamation Act (SMCRA)". Mining permit is very import requirement in this regulation. Approximately $40 \%$ of USA coal originates in an ecologically sensitive area of semi-arid shortgrass prairie in Wyoming. The second paper introduced the practice and experience of surface coal mine permit application for successful reclamation in Wyoming. The permit application includes adjudication information, baseline information, mine and operation plans, and reclamation plans. Fulfillment of permit commitments and requirements of rules and regulations are inspected monthly by the LQD's representative in the field. Before a mine permit is issued, the mine operator must submit a reclamation bond to secure the performance of reclamation obligations that is later revised annually. The Bond Release Geodatabase (a GIS/GPS approach) was developed for this mine to monitor progress in meeting criteria and performance standards for incremental bond release.

Most of coal output comes from underground mining in China. Underground mining usually results a lot of subsidence land, which creates farmland damages and environmental problems. Most reclamation practice is generally done after subsiding lands have achieved the final subsidence basin or final settlement condition after mining. However, with all these approaches over $50 \%$ of the 
agricultural land may be already submerged into water, including some with highly fertile topsoil. A new technology called CMR-UM (concurrent mining and reclamation for underground mining) was developed in China, which is done before or during the subsidence process. The paper three introduced this technology's concepts, design and guiding principles for planning with two case studies from different regions to enhance its application both in China and in other countries. The paper four developed another subsidence reclamation technology, which is the reclamation of mining subsidence land with Yellow River sediments. After introducing the technology, several typical physical properties of reclaimed farmland filled with Yellow River sediment in Jining were assessed for improving the technology and soil quality. The paper five developed a biotechnology for improving plant growth and their root development by inoculating arbuscular mycorrhizal fungi (AMF) in coal mine subsided areas. The results showed that AMF improved the shoot and root growth of Amygdalus pcdunculata Pall., and significantly increased root colonization after 1 year of inoculation. Available phosphorus content, activities of phosphatase as well as electrical conductivity in soil rhizosphere of all the three inoculation treatments were higher than that of the noninoculated treatment.

Coal wastes is the main pollution source in mining areas. The paper six studied an alternate technology for control of sulfate and chloride discharge. This research evaluates the hypothesis that co-disposal of CCPW (Coarse Coal Processing Waste) and FCPW (Fine Coal Processing Waste) with appropriate compaction can result in improved geochemical and geotechnical environments that will minimize acid mine drainage (AMD) formation and $\mathrm{SO}_{4}{ }^{2-}$ and $\mathrm{Cl}^{-}$discharges. Addition of ground limestone (aglime) to the mix was also evaluated as a drying agent and for improvement in overall geochemistry by buffering higher $\mathrm{pH}$ values within the coal waste. Coal fly ash (CFA) and municipal sewage sludge (MSS) management is a great concern worldwide. The paper seven was to present very briefly the results of some case studies carried out in China and Greece related to land reclamation and agricultural use of CFA and MSS separately or combined. The paper eight is related to soil flushing technology, which is an 'in situ' remediation technique involving the injection of a liquid solution. The applicability of the soil flushing technique for different heavy metal contents and $\mathrm{pH}$ conditions of the flushing solution was discussed in this paper.

For restoring better eco-system, a new concept called green infrastructure was presented, which aimed at realizing a strategically planned network of valuable natural and semi-natural areas, designed and managed to deliver a wide range of ecosystem services and to protect biodiversity in rural and urban settings. The paper nine suggests and outlines an approach that combines green infrastructure with specific concepts of post-mining landscapes. Taking Xuzhou urban area as the study object, the paper ten proposed a green infrastructure construction method based on the principle of ecological priority. The last paper studied the vegetation change of Dunhuang city based on GF-1 data.

Green development is priority in China. Coal mined land reclamation could play importing role in developing green mining. The purpose of this special issue is for readers paying much attention on the field of land reclamation and ecological restoration.

Open Access This article is distributed under the terms of the Creative Commons Attribution 4.0 International License (http://crea tivecommons.org/licenses/by/4.0/), which permits unrestricted use, distribution, and reproduction in any medium, provided you give appropriate credit to the original author(s) and the source, provide a link to the Creative Commons license, and indicate if changes were made. 